\title{
CARACTERÍSTICAS FÍSICO-gUímicas DE AMOSTRAS DE MEL DE Melipona mandacaia SMITH (HYMENOPTERA: APIDAE) ${ }^{1}$
}

\author{
Rogério Marcos de Oliveira ALVES ${ }^{2}$, Carlos Alfredo Lopes de CARVALHO ${ }^{3, *}$, \\ Bruno de Almeida SOUZA², Geni da Silva SODRÉ ${ }^{4}$, Luis Carlos MARCHINI ${ }^{4}$
}

\begin{abstract}
RESUMO
Análises de amostras de mel da abelha Melipona mandacaia provenientes do município de São Gabriel, região semi-árida do Estado da Bahia, foram realizadas com o objetivo de contribuir para o conhecimento das características físico-químicas desse produto. Os parâmetros analisados foram: Umidade (\%); Hidroximetilfurfural (mg. $\mathrm{kg}^{-1}$ ); Açúcares Redutores (\%); Sacarose (\%); Viscosidade (mPa. s); Condutividade Elétrica $(\mu \mathrm{S})$; pH; Acidez (meq. $\left.\mathrm{kg}^{-1}\right)$; Índice de Formol (mL. $\left.\mathrm{kg}^{-1}\right)$; e Cor. A maioria dos parâmetros físico-químicos apresentou valores médios adequados para o consumo humano, o que possibilita a exploração desse produto pelas comunidades rurais da região semi-árida da Bahia. Contudo, o teor de umidade elevado é um aspecto que requer uma maior atenção por parte do produtor, que deverá ter maiores cuidados com a higiene na manipulação do mel durante a coleta e no processo de armazenamento, evitando a sua contaminação por microrganismos que causam a depreciação do produto.

Palavras-chave: abelha sem ferrão, meliponicultura, controle de qualidade.
\end{abstract}

\section{SUMMARY}

PHYSICO-CHEMICAL CHARACTERISTICS OF HONEY SAMPLES OF STINGLESS BEE Melipona mandacaia SMITH (HYMENOPTERA APIDAE). Honey samples of the Melipona mandacaia stingless bee collected in the São Gabriel county, semi-arid region of the State of Bahia, Brazil, were analyzed with the objective of contributing for the knowledge of the characteristics physico-chemical of that product. The parameters analyzed were: Moisture (\%); Hydroxymethylfurfural (mg. $\left.\mathrm{kg}^{-1}\right)$; Reducing Sugars (\%); Sucrose

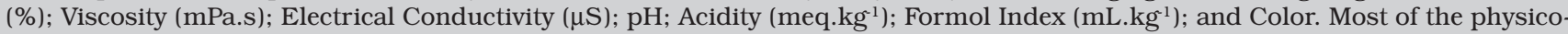
chemical parameters showed values adequated for the human consumption, facilitating the exploration of the product by rural communities of the semi-arid area of Bahia. However, the high moisture content is an aspect that deserves a greater attention by the part of producers, who should have concern with hygiene cares when manipulating the honey during the collection and the storage processes, avoiding its contamination with microorganisms that may cause depreciation of the product.

Keywords: Stingless bees, meliponiculture, quality control.

\section{1 - INTRODUÇÃO}

O mel é considerado um fluido viscoso, aromático e doce elaborado por abelhas a partir do néctar e/ou exsudatos sacarínicos de plantas, principalmente de origens florais, os quais, depois de levados para a colméia pelas abelhas, são amadurecidos por elas e estocados no favo para sua alimentação [9]. O mel é proveniente das abelhas e algumas vespas, porém devido a sua domesticação antiga e por ser originária dos principais países consumidores, a abelha Apis mellifera L. é a espécie considerada como principal produtora do mel comumente utilizado para consumo humano, apesar da grande diversidade de espécies de abelhas existentes e que produzem mel de boa qualidade, como as abelhas sem ferrão das tribos Meliponini e Trigonini.

Na história da humanidade, o mel foi uma das primeiras fontes de açúcar para o homem. Isso é demonstrado pelo uso do mel e pólen das abelhas nativas sem ferrão nos períodos pré-hispânicos e o papel que desempenharam na dieta das comunidades indígenas americanas. No Brasil até o século XIX, o mel e a cera utilizados na alimentação pelos índios e brancos e a confecção de velas pelos jesuítas eram provenientes das abelhas sem ferrão [14, 20, 21, 28].

\footnotetext{
${ }^{1}$ Recebido para publicação em 21/01/2004. Aceito para publicação em 03/10/2005 (001277).

${ }^{2}$ Programa de Pós-graduação em Ciências Agrárias - UFBA, CEP: 44380 000, Cruz das Almas-BA.

${ }^{3}$ Escola de Agronomia da UFBA, CEP: 44380-000, Cruz das Almas-BA. Bolsista do CNPq.E-mail: calfredo@ufba.br.

${ }^{4}$ ESALQ-USP, Cx. Postal 09, CEP: 13418-900, Piracicaba-SP.

*A quem a correspondência deve ser enviada.
}

As abelhas sem ferrão perfazem aproximadamente 300 espécies, sendo que a maioria é produtora de méis de grande reputação. Embora produzindo mel em menor quantidade, os meliponíneos têm o importante papel de fornecer um produto que se diferencia do mel de A. mellifera, principalmente no sabor diferenciado e no aroma, alcançando preços elevados no mercado $[4,5,14,16,20,23,28]$.

A composição do mel depende, principalmente, das fontes vegetais das quais ele é derivado, mas também de diferentes fatores, como o solo, a espécie da abelha, o estado fisiológico da colônia, o estado de maturação do mel, as condições meteorológicas quando da colheita, entre outros [10, 16, 29]. De maneira geral, o mel das espécies de meliponíneos tem como principal característica a diferenciação nos teores da sua composição, destacando-se o teor de água (umidade), que o torna menos denso que o mel das abelhas africanizadas (A. mellifera) [10]. A cor varia do quase transparente ao âmbar escuro e o gosto e níveis de açúcar dependem do paladar, da espécie, da época, da região e, principalmente, da florada [7]. Além dos açúcares em solução, o mel também contém ácidos orgânicos, enzimas, vitaminas, flavonóides, minerais e uma extensa variedade de compostos orgânicos, que contribuem para sua cor, odor e sabor [29].

Apesar da sua importância, a Legislação Brasileira que regulamenta a padronização do mel para fins de comercialização só atende às características do mel de Apis, não contemplando o mel das abelhas nativas do país [2, 7], o que leva à necessidade de estudos de diferentes méis para a sua padronização e uma futura Legislação Brasileira.

Este trabalho teve como objetivo determinar as características físico-químicas de amostras de mel de Melipona 
mandacaia provenientes de comunidades rurais da região semi-árida do Estado da Bahia, contribuindo para o conhecimento das características do mel e fornecendo subsídios para a exploração racional desse meliponíneo.

\section{2 - MATERIAL E MÉTODOS}

\section{1 - Material}

Foram utilizadas 20 amostras de mel, provenientes de 20 colônias de $M$. mandacaia localizadas na zona rural do município de São Gabriel ( $11^{\circ} 14^{\prime} \mathrm{S}$; $41^{\circ} 52^{\prime} \mathrm{W}$; altitude: 680 m), microrregião de Irecê, Estado da Bahia [34].

As colônias estavam alojadas em cortiços (pedaços de troncos de árvores) localizados em área sob forte influência humana, circundada por vegetação de caatinga arbórea densa.

A coleta das amostras foi realizada durante o mês de maio, período da principal florada na região, cuja temperatura média foi de $26^{\circ} \mathrm{C}$ e a umidade relativa do ar média foi de $57 \%$.

De cada colônia foram retirados $100 \mathrm{~mL}$ de mel por meio de seringa descartável de $10 \mathrm{~mL}$. Foi utilizada uma seringa para cada colônia e o mel colhido foi proveniente de potes de mel operculados. O mel coletado foi transferido para recipiente de vidro, previamente esterilizado, com tampa de fecho hermético e capacidade para $100 \mathrm{~mL}$. Esses recipientes foram armazenados in locu em geladeira à temperatura de $8^{\circ} \mathrm{C}$. No transporte até o laboratório, realizado no mesmo dia, os recipientes foram acondicionados em caixa de isopor com gelo.

O material das análises foi encaminhado ao Laboratório de Insetos Úteis do Departamento de Entomologia, Fitopatologia e Zoologia Agrícola da Escola Superior de Agricultura Luiz de Queiroz, campus de Piracicaba da USP, onde foram realizadas as análises: hidroximetilfurfural, cor, açúcares redutores, sacarose, viscosidade, condutividade elétrica, pH, acidez e índice de formol.

\section{2 - Métodos}

\subsection{1 - Hidroximetilfurfural (HMF)}

O método utilizado foi o quantitativo, através da espectofotometria a 284 e $336 \mathrm{~nm}$ (METROLAB 1700 UVVIS) [8].

\subsection{2 - Umidade}

A umidade das amostras foi determinada in locu através de um refratômetro manual marca ATAGO NE3 (luz natural, temperatura ambiente) específico para mel. O referido aparelho dispõe de uma escala que expressa diretamente o valor do SST em Brix ( $\left.{ }^{\circ} \mathrm{Bx}\right)$, sendo feita uma correção em função da temperatura ambiente, obtida com um termômetro, colocado no local [3]. O cálculo da umidade é realizado pela subtração do valor de SST ( $\left.{ }^{\circ} \mathrm{Bx}\right)$ de 100.

\subsection{3 - Açúcares redutores e sacarose}

Determinados por meio do método estabelecido por Somogyi, utilizando aparelho de oxirredutimetria por titulação (REDUTEC TECNAL TE 086) [27].

\subsection{4 - Cor}

Para a determinação da cor do mel foi utilizado o espectrofotômetro (METROLAB 1700 UVVIS), com medição em 635 nm, solução a 50\% usando a glicerina como o branco [17]. As leituras obtidas foram confirmadas com o colorímetro de Pfund.

\subsection{5 - Viscosidade}

Determinado em viscosímetro digital (BROOKFIELD, modelo DV-I+), acoplado a banho termostático, à temperatura de $25^{\circ} \mathrm{C} \pm 1^{\circ} \mathrm{C}$ a $1,5 \mathrm{rpm}$ [10].

\subsection{6 - Condutividade Elétrica}

Obtida em uma solução de $20 \%$ de matéria seca de mel a $20^{\circ} \mathrm{C}$, determinado com condutivímetro (HANNA INSTRUMENTS, modelo HI 8820N) [32].

\subsection{7 - pH, acidez e índice de formol}

Determinados segundo metodologia adotada pelo Laboratório do Centro de Apicultura Tropical do Instituto de Zootecnia de Pindamonhangaba, Estado de São Paulo, baseada em titulação simples, utilizando pHmetro (Digimed DMPH-1) para acompanhar a medida do $\mathrm{pH}$ [25].

\section{3 - RESULTADOS E DISCUSSÃO}

Os dados médios obtidos a partir da análise das amostras de mel provenientes de 20 colônias de $M$. mandacaia encontram-se na Tabela 1.

TABELA 1 - Análise físico-química de amostras de mel de Melipona mandacaia (Hymenoptera: Apidae: Meliponinae)

\begin{tabular}{|c|c|c|c|c|c|c|}
\hline Parâmetros & $\mathbf{n}$ & Média & $\begin{array}{l}\text { Desvio } \\
\text { padrão }\end{array}$ & Mínimo & Máximo & $\begin{array}{c}\text { Coeficiente } \\
\text { de } \\
\text { Variação } \\
(\%)\end{array}$ \\
\hline Umidade (\%) & 20 & 28,78 & 2,73 & 23,14 & 32,50 & 9,49 \\
\hline $\operatorname{HMF}^{1}\left(\mathrm{mg} \cdot \mathrm{kg}^{-1}\right)$ & 20 & 5,79 & 5,33 & 0,52 & 16,54 & 92,06 \\
\hline $\operatorname{AR}^{2}(\%)$ & 20 & 74,82 & 4,28 & 64,29 & 82,10 & 5,72 \\
\hline Sacarose (\%) & 20 & 2,91 & 1,65 & 0,61 & 6,19 & 56,70 \\
\hline $\begin{array}{l}\text { Viscosidade } \\
\text { (mPa.s) }\end{array}$ & 20 & 59,60 & 28,25 & 24,00 & 116,00 & 47,40 \\
\hline $\begin{array}{l}\text { Condutividade } \\
(\mu S)\end{array}$ & 20 & 352,25 & 48,71 & 267,50 & 462,00 & 13,83 \\
\hline $\mathrm{pH}$ & 20 & 3,27 & 0,09 & 3,16 & 3,54 & 2,75 \\
\hline $\begin{array}{l}\text { Acidez } \\
\left(\text { meq. } \mathrm{kg}^{-1}\right)\end{array}$ & 20 & 43,48 & 10,35 & 18,50 & 62,50 & 23,80 \\
\hline $\begin{array}{l}\text { Índice de } \\
\text { formol }\left(\mathrm{mL} \cdot \mathrm{kg}^{-1}\right)\end{array}$ & 20 & 5,18 & 1,32 & 3,16 & 3,54 & 25,48 \\
\hline
\end{tabular}

${ }^{1} \mathrm{HMF}$ - hidroximetilfurfural; ${ }^{2} \mathrm{AR}$ - açúcares redutores; $\mathrm{n}$ - número de amostras

Uma das 20 amostras de mel de M. mandacaia apre-

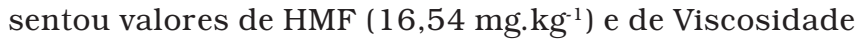
(116,00 mPa.s) muito acima da média, enquanto uma outra apresentou valores de 0,52 mg. $\mathrm{kg}^{-1}$ e 24,00 mPa.s, o que elevou o Coeficiente de Variação (CV\%) desses dois 
parâmetros. De forma semelhante, foram encontrados valores entre 0,61\% e 6,19\% de Sacarose, contribuindo para a elevação do CV(\%) desse açúcar.

A análise das amostras expõe algumas diferenças entre os parâmetros observados na análise do mel de $M$. mandacaia em relação aos valores estipulados pela Instrução Normativa no 11 do MAPA - Ministério da Agricultura, Pecuária e Abastecimento [9], Resolução no 88/99 do Mercosul [24] e do padrão para o mel do Codex Alimentarius [13] (Tabela 2). De acordo com PAMPLONA [30], não existe no Brasil uma norma baseada nas características dos méis brasileiros, sendo seguidos limites oriundos de outros países como a norma da Comunidade Econômica Européia e o "Codex Alimentarius", cujos limites para a composição e qualidade do mel são estabelecidos de acordo com as especificações da FAO, que entende como mel um produto com características baseadas apenas na espécie $A$. mellifera, única espécie melífera originária do continente euro-africano.

TABELA 2 - Parâmetros estabelecidos pela Legislação Brasileira, Legislação Mercosul e do Codex Alimentarius para o mel floral e os valores médios obtidos para amostras de mel de Melipona mandacaia

\begin{tabular}{|c|c|c|c|c|}
\hline Parâmetros & $\begin{array}{c}\text { Legislação } \\
\text { Brasileira } \\
\text { [9] }\end{array}$ & $\begin{array}{l}\text { Legislação } \\
\text { do } \\
\text { Mercosul [24] }\end{array}$ & $\begin{array}{c}\text { "Codex } \\
\text { Alimentarius" } \\
{[13]}\end{array}$ & $\begin{array}{c}\text { Valores } \\
\text { médios } \\
\text { obtidos nas } \\
\text { amostras } \\
\text { de mel }\end{array}$ \\
\hline Umidade (\%) & $\begin{array}{c}\text { Máximo de } \\
20,00\end{array}$ & $\begin{array}{c}\text { Máximo de } \\
20,00\end{array}$ & $\begin{array}{c}\text { Máximo de } \\
20,00\end{array}$ & 28,78 \\
\hline $\begin{array}{l}\mathrm{HMF}^{1} \\
\left(\mathrm{mg} \cdot \mathrm{kg}^{-1}\right)\end{array}$ & $\begin{array}{c}\text { Máximo de } \\
60,00\end{array}$ & $\begin{array}{c}\text { Máximo de } \\
60,00\end{array}$ & $\begin{array}{l}\text { Máximo } \\
\text { de } 80,00 \\
\text { em regiões } \\
\text { tropicais }\end{array}$ & 5,79 \\
\hline $\mathrm{AR}^{2}(\%)$ & $\begin{array}{c}\text { Mínimo de } \\
65,00\end{array}$ & $\begin{array}{l}\text { Mínimo de } \\
65,00\end{array}$ & $\begin{array}{c}\text { Mínimo de } \\
60,00\end{array}$ & 74,82 \\
\hline $\begin{array}{l}\text { Sacarose } \\
(\%)\end{array}$ & $\begin{array}{c}\text { Máximo de } \\
6,00\end{array}$ & $\begin{array}{c}\text { Máximo de } \\
6,00\end{array}$ & $\begin{array}{c}\text { Máximo de } \\
5,00\end{array}$ & 2,91 \\
\hline $\begin{array}{l}\text { Condutividade } \\
(\mu S)\end{array}$ & - & - & $\begin{array}{c}\text { Máximo de } \\
800\end{array}$ & 352,25 \\
\hline $\begin{array}{l}\text { Acidez } \\
\left(\text { meq. } \mathrm{kg}^{-1}\right)\end{array}$ & $\begin{array}{c}\text { Máximo de } \\
50,00\end{array}$ & $\begin{array}{c}\text { Máximo de } \\
50,00\end{array}$ & $\begin{array}{c}\text { Máximo de } \\
50,00\end{array}$ & 43,48 \\
\hline Cor & $\begin{array}{l}\text { Incolor } \\
\text { a pardo- } \\
\text { escuro }\end{array}$ & $\begin{array}{c}\text { De quase } \\
\text { incolor a } \\
\text { pardo- escuro }\end{array}$ & $\begin{array}{c}\text { Incolor a } \\
\text { pardo-escuro }\end{array}$ & $\begin{array}{l}\text { Dentro do } \\
\text { padrão }\end{array}$ \\
\hline
\end{tabular}

${ }^{1} \mathrm{HMF}$ - hidroximetilfurfural; ${ }^{2} \mathrm{AR}$ - açúcares redutores

A utilização generalizada dos valores referentes aos parâmetros físico-químicos do mel de uma determinada espécie de abelha sem ferrão poderá acarretar problemas quando da comercialização desse produto no mercado interno e externo, porque não há ainda dados consistentes para a padronização do mel de meliponíneos.

Os dados obtidos demonstram que as características físico-químicas do mel da $M$. mandacaia são diferentes na sua composição do mel de A. mellifera.

\section{1 - Umidade}

A umidade (\%) para as 20 amostras de méis analisadas apresentou média de 28,78 $\pm 2,73 \%$ (Tabela 1 ), o que de- monstra que $100 \%$ das amostras estão acima dos limites especificados nas legislações nacional e internacional para o mel de Apis.

Pelos resultados obtidos observa-se que os méis dessa espécie apresentam valores acima dos encontrados para $A$. mellifera, que varia entre 15 a 25\% [9]. Entretanto estão próximos aos resultados de outras espécies do gênero $\mathrm{Me}$ lipona [15, 23, 36].

Estudos sobre as características físico-químicas dos méis de $M$. scutellaris provenientes dos Estados da Bahia e da Paraíba apresentaram valores de umidade da ordem de 28,40\% [23]; 24 - 29\% [15] e 25,26\% [18]. Para o mel de $M$. compressipes fasciculata também, foi observada uma variação dependendo da região: 26,94\% no Maranhão [20]; 25\% no Piauí [37] e 27\% no Tocantins [6]. Determinações realizadas para a espécie $M$. quadrifasciata constataram teores de 27,2\% no Maranhão e 34,0\% em São Paulo [1, 20]. No México, amostras de méis de $M$. beechei apresentaram valores de 27,0\% [11].

O excesso de água encontrado no mel dos meliponíneos é devido à baixa taxa de desidratação do néctar durante o processo de transformação em mel. Méis de espécies de habitat úmidos (e.g.: M. scutellaris) normalmente apresentam um conteúdo maior de água, que é influenciado pelas condições ambientais [15]. Entretanto, os valores obtidos para méis de $M$. mandacaia demonstram que, apesar do clima seco, o teor de umidade nos méis dessas abelhas mantém valores altos, acima dos estabelecidos pela legislação. Resultados semelhantes foram encontrados para méis de $M$. asilvai na Bahia (29,49\%) [36].

Amostras de méis de espécies de Melipona da zona árida do Estado da Bahia apresentaram valores da ordem de 27 a $30 \%$ para $M$. asilvai, 25 a $32 \%$ para $M$. mandacaia e 27 a 34\% para M. quadrifasciata anthidioides [12].

\section{2 - Açúcares Redutores}

O conteúdo de açúcares redutores obtido nas amostras analisadas variou de $64,29 \%$ a $82,10 \%$ e obteve média de $74,82 \pm 4,28 \%$ (Tabela 1 ). As normas nacionais estabelecem mínimo de 65 \% e o "Codex Alimentarius" de 60,0\%, sendo que o resultado médio obtido encontra-se dentro dos parâmetros exigidos para o mel de Apis.

Méis de $A$. mellifera apresentaram valores de açúcares redutores na ordem de 53,2\% [22] e 80,3\% [35]. Estudo sobre o mel de M. asilvai indicou o valor médio de $68,9 \%$ para esse parâmetro [36].

Méis de melíponas possuem menor teor em açúcares (70\%) e gosto mais doce. Os principais açúcares encontrados no mel são a glicose e a frutose, em proporções quase iguais [20], sendo importantes para o estabelecimento de uma série de características deste produto [26]. Normalmente a frutose é predominante, sendo um dos fatores responsáveis pela doçura do mel e sua alta higroscopicidade [16]. Méis com altas taxas de frutose podem permanecer líquidos por longos períodos ou nunca cristalizar [19]. 
Apesar das médias das amostras estarem dentro dos parâmetros, nota-se uma variação muito acentuada dos teores de açúcares redutores, decorrente provavelmente da influência da flora local.

\section{3 - Sacarose}

A porcentagem de sacarose das 20 amostras analisadas varia de 0,61 a $6,19 \%$, com valor médio $2,91 \pm 1,65 \%$. As normas para méis de Apis estabelecem um máximo de 6,00\% [9, 24] para méis de origem floral. Na avaliação da média, 95\% das amostras estão abaixo do limite máximo permitido.

Os valores observados estão próximos aos encontrados para méis de $A$. mellifera da Bahia (2,40\%) [35] e de São Paulo (4,50\%) [1]. Para méis de M. asilvai, o valor obtido foi $4,70 \%$ [36].

Há uma grande variação na distribuição da sacarose nas amostras de mel nos diversos trabalhos encontrados na literatura [26]. A concentração de sacarose constitui um bom critério para diferenciar os méis monoflorais dos poliflorais [11]. O teor elevado deste açúcar significa na maioria das vezes uma colheita prematura do mel, isto é, um produto em que a sacarose ainda não foi totalmente transformada em glicose e frutose pela ação da invertase [7].

\section{4 - Acidez}

Os valores da acidez para as amostras analisadas variaram entre 18,50 e 62,50 meq. $\mathrm{kg}^{-1}$, com média de $43,48 \pm 10,35$ meq. $\mathrm{kg}^{-1}$, estando em conformidade com as normas nacionais e internacionais para méis de Apis.

O teor médio de acidez das amostras encontra-se próximo ao limite máximo das legislações vigentes, sendo semelhantes aos encontrados para os méis de $M$. compressipes no Piauí (45,75 meq. $\mathrm{kg}^{-1}$ ) [37] e M. asilvai na Bahia (41,64 meq. $\mathrm{kg}^{-1}$ ) [36]. Entretanto, méis de $M$. scutellaris apresentaram valores médios de 8,88 meq. $\mathrm{kg}^{-1}$ oriundos da Bahia [23] e 28,33 meq. $\mathrm{kg}^{-1}$ da Paraíba [18]. Em amostras de $M$. quadrifasciata foi encontrada acidez da ordem de 16,5 meq. $\mathrm{kg}^{-1}[1]$.

O resultado médio das análises de méis de $A$. mellifera provenientes de quatro regiões brasileiras foi de 37,1 meq. $\mathrm{kg}^{-1}$ [19]. De acordo com esse autor, todos os méis são ácidos, sendo o ácido glucônico produzido pela enzima glicose-oxidase sobre a glicose o mais comum. A ação desta enzima se mantém mesmo durante o armazenamento, pois permanece em atividade no mel mesmo após o processamento [28]. A acidez é importante na manutenção da estabilidade, reduzindo o risco de desenvolvimento de microorganismos [33].

No Codex Alimentarius a acidez máxima é de 50 meq. $\mathrm{kg}^{-1}$, embora existam alguns tipos de méis nas regiões tropicais que apresentam um teor natural de acidez mais elevado [8]. Como a acidez influencia diretamente o sabor do mel, pode-se explicar a notável preferência do consumidor pelo sabor do mel da abelha nativa [18].

\section{5 - Cor}

A análise do mel dessa espécie demonstrou uma coloração variando entre o branco e o âmbar claro, predominando o âmbar claro na maior parte das amostras (50\%) (Figura 1).

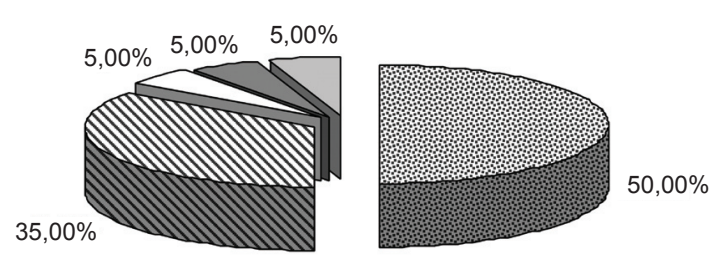

图âmbar claro Nextra branco $\square$ branco água $\square$ âmbar extra claro $\square$ branco

FIGURA 1 - Coloração das amostras de mel de Melipona mandacaia

Em méis de $M$. compressipes também, predominou a cor âmbar claro [6], enquanto para amostras de M. quadrifasciata houve predomínio da cor âmbar extra claro [1] e nas de $M$. asilvai [36] e M. scutellaris [23] predominou o branco.

As amostras analisadas estão dentro dos padrões exigidos pela legislação, que classifica o mel do incolor ao âmbar escuro. A cor do mel líquido pode, realmente, variar de branco-aquoso a próximo de preto, com variantes tendendo para matizes de verde ou vermelho, ou mesmo azul [16].

A cor do mel está associada à sua origem floral, porém as substâncias responsáveis pela cor são ainda desconhecidas [29]. Acredita-se que minerais estejam entre os fatores responsáveis; entretanto, o armazenamento prolongado, a luz, as possíveis reações enzimáticas, aquecimento e o processo de colheita podem escurecer o mel [16].

Nos mercados mundiais o mel é avaliado por sua cor, sendo que méis mais claros alcançam preços mais elevados [12]. A predominância de cores claras nos méis de meliponíneos pode resultar num produto de alta aceitação no mercado internacional.

\section{6 - Hidroximetilfurfural (HMF)}

O resultado médio de HMF foi de 5,79 $\pm 5,33 \mathrm{mg} \cdot \mathrm{kg}^{-1}$, indicando que $100 \%$ das amostras estão abaixo do valor máximo estabelecido pela legislação nacional e internacional para méis de Apis.

O HMF encontrado em amostras de méis de outras espécies de Melipona também apresentou valores baixos, como em M. asilvai (2,44 mg. $\mathrm{kg}^{-1}$ ) [38], M. quadrifasciata (1,03 mg. $\mathrm{kg}^{-1}$ ) [1] e M. scutellaris (0,38 mg. $\mathrm{kg}^{-1}$ ) [23].

Uma pequena quantidade de HMF é encontrada em méis recém-colhidos [19]. Esta substância é formada pela reação de certos açúcares com ácidos, sendo a frutose considerada a principal formadora do composto, devido à ação de ácidos e do calor. Além disso, o conteúdo de HMF no mel também pode ser afetado pela acidez, $\mathrm{pH}$, conteúdo de água e minerais [38]. 
Méis com taxas maiores de frutose dão origem a maiores taxas de HMF ao longo do armazenamento [19]. A quantidade de HMF observada numa análise de mel pode ser utilizada como indicador de qualidade, sendo que os valores aumentam mais rapidamente em méis submetidos a altas temperaturas por superaquecimento e armazenamento [16].

Mesmo em ambiente com temperaturas altas, como na região onde habita a $M$. mandacaia, os méis desse meliponíneo apresentaram baixos teores de HMF, sendo que o valor mais alto foi $16,54 \mathrm{mg} \cdot \mathrm{kg}^{-1}$, inferior ao encontrado para méis de $A$. mellifera provenientes do nordeste brasileiro (média igual a 24,33 mg. $\mathrm{kg}^{-1}$ ) [35].

Valores elevados de HMF encontrados nos méis de meliponíneos podem estar associados às técnicas inadequadas de manejo e/ou condições climáticas adversas da região [31].

A recomendação do Codex Alimentarius prevê uma taxa máxima de $80 \mathrm{mg} . \mathrm{kg}^{-1}$ de HMF, para méis provenientes de países tropicais. Esta recomendação de uma taxa máxima mais elevada baseia-se no fato de, nos países quentes, o teor de HMF do mel aumentar mais rapidamente durante o tempo de armazenamento [8].

\section{7 - Condutividade}

A análise das 20 amostras apresentou uma condutividade média de $352,25 \pm 48,71 \mu \mathrm{S}$, com variação entre 267,50 e $462,00 \mu \mathrm{S}$. Os valores estão abaixo dos exigidos pelo Codex Alimentarius que é de $800 \mu \mathrm{S}$. Este parâmetro não é padronizado pelas normas brasileiras e do Mercosul.

Os valores encontrados para o mel de $M$. mandacaia são semelhantes aos obtidos para méis de $M$. scutellaris $(332,92 \mu \mathrm{S})$ [23] e M. asilvai $(362,86 \mu \mathrm{S})$ [36].

Méis de A. mellifera analisados por diferentes autores apresentaram valores mais altos que os de meliponíneos para esse parâmetro [1, 19, 35].

A condutividade elétrica do mel depende dos ácidos orgânicos e dos sais minerais, além das proteínas e de algumas outras substâncias [16, 19]. Apesar de não ser exigida pela Legislação Brasileira, a condutividade elétrica é considerada um bom critério para a determinação botânica do mel e atualmente substitui a análise de teor de cinzas, pois essa medição é diretamente proporcional ao teor de cinzas na acidez do mel [8].

\section{$3.8-\mathrm{pH}$}

O valor médio de pH obtido foi de 3,27 $\pm 0,09$ com variação entre 3,16 e 3,54. Os valores de pH não estão padronizados pela legislação nacional ou internacional.

O pH encontrado para o mel de $M$. mandacaia está próximo do obtido para o mel de $M$. scutellaris $(3,15)$ [23] e M. asilvai $(3,27)$ [36]. Entretanto, é inferior ao encontrado para M. quadrifasciata $(4,52)$ [1].
O mel de $M$. beechei apresentou uma variação de 3,6 a 5,1 [11]. Normalmente o pH dos méis é baixo, sendo que méis com origem botânica definida possuem características distintas de $\mathrm{pH}$ [29].

O valor de $\mathrm{pH}$ do mel pode ser influenciado pelo $\mathrm{pH}$ do néctar, solo ou associação de vegetais para composição do mel [16]. Substâncias mandibulares da abelha acrescidas ao néctar quando do transporte até a colméia também podem alterar o pH do mel [18]. O pH do mel é importante por influenciar na velocidade de formação do HMF [37].

\section{9 - Índice de formol}

O resultado médio obtido a partir das amostras de méis de M. mandacaia foi de 5,18 $\pm 1,32 \mathrm{~mL} \cdot \mathrm{kg}^{-1}$.

Apesar dos escassos trabalhos que avaliam esse índice, os valores obtidos são semelhantes aos de M. asilvai $(5,27$ mL.kg-1) [36] e abaixo dos encontrados para méis de $M$. scutellaris (7,36 mL. $\left.\mathrm{kg}^{-1}\right)$ [23] e M. quadrifasciata (4,00 $\mathrm{mL} . \mathrm{kg}^{-1}$ ) [1].

Para amostras de mel silvestres de A. mellifera, os valores variaram de 9,22 mL. $\mathrm{kg}^{-1}$ [35] a 10,10 mL. $\mathrm{kg}^{-1}$ [22].

Este índice não consta das características de avaliação da qualidade do mel pelas legislações vigentes. Porém, constitui um parâmetro muito importante no mel por representar uma medida global dos compostos aminados, o que permite avaliar o conteúdo de proteínas e aminoácidos. Em geral, a maior importância dos aminoácidos é que eles podem fornecer caracteres que distinguem os tipos de méis entre si e de méis falsificados [16].

\subsection{0 - Viscosidade}

As amostras de méis apresentaram a média de 59,60 $\pm 28,25 \mathrm{mPa}$.s para a viscosidade, sendo que a variação foi de 24,00 a $116,00 \mathrm{mPa} . \mathrm{s}$.

Amostras de $M$. asilvai apresentaram valores próximos aos obtidos neste estudo (66,55 mPa.s) [36].

A viscosidade de um mel depende grandemente do seu conteúdo de água e está assim ligada a sua densidade relativa; quanto menos água, mais altas a densidade e viscosidade [16]. Méis de meliponíneos caracterizam-se pela fluidez, devido ao alto teor de água, o que pode ser uma vantagem quando do envasamento e da decantação por menor período.

Apesar da sua importância, a viscosidade dos méis não constitui critério de avaliação nas legislações vigentes.

\section{4 - CONCLUSÕES}

A maioria dos parâmetros físico-químicos obtidos nas amostras de mel de Melipona mandacaia apresentou valores adequados para o consumo humano, o que possibilita a exploração desse produto pelas comunidades rurais da região semi-árida da Bahia. 
O mel de M. mandacaia possui características físicoquímicas distintas do mel de Apis mellifera, o que assegura um nicho de mercado como produto diferenciado.

Dentre as características físico-químicas analisadas neste trabalho, apenas o teor de umidade encontra-se fora dos padrões definidos pela legislação que trata da definição do produto mel.

\section{5 - REFERÊNCIAS BIBLIOGRÁFICAS}

[1] ALMEIDA, D.; MARCHINI, L.C. Physicochemical and pollinic composition of honey samples of stingless bees (Hymenoptera: Apidae: Meliponini) from the "cerrado" of Pirassununga campus, University of São Paulo, in Pirassununga, State of São Paulo, Brazil. In: Proceedings of the 8th IBRA International Conference on Tropical Bees and VI Encontro sobre Abelhas, Ribeirão Preto, SP, 2004, p. 585.

[2] AMAVIDA. Mel de abelhas nativas no mercado. Disponível em: http//www.amavida.org.br. Acesso: $15 \mathrm{de}$ dezembro de 2002.

[3] ATAGO Co. Refratômetro para mel. Abelhas, v. 31, n. 362/363, p. 9, 11-12, 41, 44, 1988.

[4] ALVES, R. M. de O.; SOUZA, B. de A.; CARVALHO, C. A. L. de; JUSTINA, G. D. Custo de produção de mel: uma proposta para abelhas africanizadas e meliponíneos. Cruz das Almas: Universidade Federal da Bahia/SEAGRI. 2005. 14 p. (Série Meliponicultura - 02).

[5] ALVES, R. M. de O.; CARVALHO, C. A. L. de; SOUZA, B. de A.; JUSTINA, G. D. Sistema de produção para abelhas sem ferrão: uma proposta para o estado da Bahia. Cruz das Almas: Universidade Federal da Bahia/ SEAGRI. 2005. 18 p. (Série Meliponicultura - 03).

[6] AZEREDO, L. C.; AZEREDO, M. A. A.; BESER, L. B. de O.; COSTA, V. C. S.; SILVA, V. A. G. da. Características físico-químicas de amostras de méis de melíponas coletadas no estado de Tocantins. In: XIII Congresso Brasileiro de Apicultura, Florianópolis, SC, 2000. 1 CD-rom.

[7] AZEREDO, M. A. A.; AZEREDO, L. da C.; DAMASCENO, J. G. Características físico-químicas dos méis do município de São Fidélis - RJ. Ciência e Tecnologia de Alimentos, v. 19, n. 1 , p. 3-7, 1999.

[8] BOGDANOV, S.; MARTIN, P.; LULLMAN, C. Harmonized methods of the European honey commission. Apidologie, p. 1-59, 1997.

[9] BRASIL, Ministério da Agricultura, Pecuária e Abastecimento, Instrução Normativa 11 , de 20 de outubro de 2000, Regulamento técnico de identidade e qualidade do mel. Disponível em: http://www.agricultura. gov.br/das/dipoa/anexo_intrnorm 11. htm. Acesso em: 20 de outubro de 2003.

[10] CAMPOS, G.; MODESTA, R. C. D. Diferenças sensoriais entre mel floral e mel de melato. Revista do Instituto Adolfo Lutz, v. 59, n. 1-2, p. 7-14, 2000.

[11] CARILLO MAGANA, F.A. Meliponicultura: el mundo de las abejas nativas de Yucatán. Mérida, México. 1998.

[12] CARVALHO, C. A. L. de; ALVES, R. M.de O.; SOUZA, B de A. Criação de abelhas sem ferrão: aspectos práticos. Cruz das Almas: Universidade Federal da Bahia/SEAGRI, 2003. 42 p. (Série Meliponicultura - 01).
[13] CODEX ALIMENTARIUS. Revised codex standard for honey. Rev. 2 [2001]. $24^{\text {th }}$ session of the Codex Alimentarius in 2001. Disponível em: http/ www.codexalimentarius. net/standard. Acesso: 20 de outubro de 2003.

[14] CORTOPASSI-LAURINO, M. Abelhas em agronegócios. VI Seminário Nordestino de Pecuária - Apicultura, Fortaleza,CE, 2002. p. 5-11.

[15] CORTOPASSI-LAURINO, M.; MONTENEGRO DE AQUINO, H. Forrageamento na abelha uruçu (Melipona scutellaris). In: XIII Congresso Brasileiro de Apicultura, Florianópolis, SC, 2000. 1 CD-rom.

[16] CRANE, E. O livro do mel. $2^{\text {a }}$ edição. São Paulo: Nobel, 1985. $226 \mathrm{p}$.

[17] ESCOBAR-MARTINEZ, C. A.; GIMENEZMEZA, G. G.; MENDONZA, Q. M. R. Mieles de abejas de flor paraguaya: composición, tipificación y normalización. San Lorenzo: Ministerio da Agricultura y Ganaderia/ Universidad Nacional de Assunción/Asociación Suiza para el Desarrollo y la Cooperación. 1992.

[18] EVANGELISTA-RODRIGUES, A.; SILVA, E. M. S. da; BEZERRA, E. M. F. Análises físico-químicas de méis de abelhas Apis mellifera e Melipona scutellaris. Disponível em: http//www.agroline.com.br/agrociencia/pdf. Acesso: 2003.

[19] HORN, H. Méis Brasileiros: resultados de análises físicoquímicas e palinológicas. In: XI Congresso Brasileiro de Apicultura, Teresina, PI, 1996. p. 403-429.

[20] KERR, W.E. Biologia e manejo da Tiúba, a abelha do Maranhão. São Luís: Edufma, 1996. 156 p.

[21] KERR, W. E.; CARVALHO, G. A.; NASCIMENTO, V. A. A abelha uruçu: biologia, manejo e conservação. Belo Horizonte: Acanjaú, 1996. 143 p.

[22] KOMATSU, S. S. Caracterização físico-química de méis de Apis mellifera L., 1758 (Hymenoptera: Apidae) de diferentes municípios do estado de São Paulo. Piracicaba, 1996. 86 p. Tese (Doutorado) - Escola Superior de Agricultura Luiz de Queiroz (ESALQ).

[23] MARCHINI, L. C.; CARVALHO, C. A. L. de; ALVES, R. M. de O.; TEXEIRA, G. M.; OLIVEIRA, P. C. F. de; RUBIA, V. R. Características físico-químicas de amostras de méis da abelha uruçu (Melipona scutellaris). In: XII Congresso Brasileiro de Apicultura, Salvador, BA, 1998. p. 201.

[24] MERCOSUL. Grupo de Mercado Comum. Resolução n. 88/99. Regulamento Técnico Mercosul: "Identidade e Qualidade do Mel". Disponível em: http//www. mercosur.org.uy/português/normativa. Acesso: $20 \mathrm{de}$ outubro de 2003.

[25] MORAES, R. M. de; TEIXEIRA, E.W. Análise de mel. Pindamonhagaba: Instituto de Zootecnia. 1998. 41 p. Manual Técnico.

[26] MOREIRA, R. F. A.; MARIA, C. A. B de. Glicídios no mel. Química Nova, v. 24, n. 4, p. 516-525, 2001.

[27] NELSON, N. A. A photometric adaptation of the Somogyi method for the determination of glucose. Journal of Biological Chemistry, v. 153, p. 375, 1944.

[28] NOGUEIRA-NETO, P. Vida e Criação de Abelhas Indígenas Sem Ferrão. São Paulo: Nogueirapis. 1997. 446 p.

[29] PAMPLONA, B. C. Exame dos elementos químicos inorgânicos encontrados em méis brasileiros de Apis mellifera e suas relações físico-biológicas. São Paulo, 1989.131 p. Dissertação (Mestrado) - Instituto 
de Biologia, Universidade de São Paulo (USP).

[30] PAMPLONA, B. Qualidade do mel. In: IX Congresso Brasileiro de Apicultura, Rio Quente, GO, 1994. p. 353-356.

[31] REGO, J. G. S.; XIMENES, R. S. S.; CARNEIRO, J. G. M. Qualidade de méis de Apis mellifera através de parâmetros físico-químicos. V Encontro Sobre Abelhas de Ribeirão Preto, Ribeirão Preto, SP, 2002, p. 284.

[32] RENDÓN, S. R. Estudio de la composición físicoquímica de las mieles extremenas y extranjeras. In: V Congresso Ibero-Latinoamericano de Apicultura, Montevidéu, Uruguai, 1996, p. 174-183.

[33] SEEMANN, P.; NEIRA, M. Tecnología de la producción apícola. Valdivia: Universidad Austral de Chile, Facultad de Ciencias Agrarias Empaste, 1988.

[34] SEI. Superintendência de Estudos Econômicos e Sociais da Bahia. Estatísticas dos Municípios Baianos. Secretaria de Planejamento e Ciência Tecnológica. Salvador, 2002. v. 2. 1 CD.
[35] SODRÉ, G. da S.; MARCHINI, L. C.; MORETI, A. C. de C. C.; CARVALHO, C. A. L. de. Análises multivariadas com base nas características físico-químicas de amostras de méis de Apis mellifera L. (Hymenoptera: Apidae) da região litoral norte do Estado da Bahia. Archivos Latinoamericanos de Producción Animal, v. 11, n. 3, p. 129-137, 2003.

[36] SOUZA, B. de A.; CARVALHO, C. A. L. de; SODRÉ, G. da S.; MARCHINI, L. C. Características físico-químicas de amostras de mel de Melipona asilvai (Hymenoptera: Apidae). Ciência Rural, v. 34, n. 5, p. 1623-1624, 2004.

[37] SOUZA, D.C.; BAZLEN, K. Análises preliminares de características físico-químicas de méis de Tiúba (Melipona compressipes) do Piauí. In: XII Congresso Brasileiro de Apicultura, Salvador, BA, 1998, p. 267.

[38] WHITE JUNIOR, J. W. Methods for determining carbohydrates, hydroxymetilfurfural and proline in honey; collaborative study. Journal of the Association of Official Analytical Chemists, v. 62, n. 3, p. 515-526, 1979. 